\title{
ENTRE BRASIL E PORTUGAL: OS SERTÕES E 0 MITO SEBÁSTICO
}

Paulo Fernando da Motta de Oliveira

\section{RESUMO:}

Este artigo pretende analisar a presença do Sebastianismo em Os Sertões $e$ as relações existentes entre este livro e a sua principal fonte para a história portuguesa, o História de Portugal de Oliveira Martins. PALAVRAS-CHAVE:

Sebastianismo, Euclides da Cunha, Oliveira Martins.

Qualquer pesquisador do Sebastianismo e das suas múltiplas manifestações na cultura portuguesa notará que a revolta de Canudos, e em especial a forma como ela foi cristalizada em Os Sertões, é uma referência obrigatória para aqueles que estudaram os desdobramentos do mito sebástico no Brasil. Foi por este caminho que chegamos a esta obra de Euclides da Cunha, e é ele que, em certo sentido, define os limites das reflexões que aqui pretendemos tecer. Estaremos preocupados principalmente em verificar de que forma o Sebastianismo aparece em Os Sertões, e como nesta obra ele é interpretado, trabalho que exigirá, inicialmente, que teçamos algumas considerações gerais sobre este mito em seu contexto de origem, ou seja, em Portugal.

REVISTA DE ESTUDOS DE LITERATURA

Belo Horizonte, v. 4, p. $225-239$, out. 96

2त同 


\section{I - D. Sebastião, o rei de fantástica memória}

(...) onde o areal está

Ficou o meu ser que houve, não o que há.'

O mito sebástico tem uma importância fundamental na cultura portuguesa. Sua origem se relaciona com o próprio nascimento de D. Sebastião, príncipe desejado como a única possibilidade de manutenção da independência portuguesa. Como sabemos, seu avô, D. João III, tivera onze filhos legítimos, dos quais apenas dois ultrapassaram a infância: D. Maria, que morreu pouco depois de dar a luz a seu filho com Felipe de Espanha, e D. João, que também veio a falecer, antes mesmo do nascimento de seu filho. Estes acontecimentos, que implicavam a ausência de um herdeiro direto para o trono português, faziam do então príncipe espanhol Felipe, sobrinho de D. João III, o mais forte pretendente à sucessão deste rei. Assim D. Sebastião, ansiosamente esperado, transformou-se, como o qualificou Camões, na "bem nascida segurança / Da transformou-se, como o quá Se, já em seu nascimento, ele se configurou como o Desejado, durante a sua curta vida, outras esperanças foram nele depositadas. Eduardo Lourenço, ao analisar o período de composição de Os Lusíadas, obra que foi publicada em 1572, quatro anos após D. Sebastião ter sido coroado rei aos quatorze anos de idade, afirma:

Quando Camões refaz o percurso simbólico de Portugal como de um herói colectivo, destinado pela Providência a abrir os oceanos e a levar a mensagem de Cristo ao Oriente, (...) a descoberta de Gama tem quase um século e o teatro da Índia que ele freqüentará como desterrado, é menos um tablado épico que uma imensa feira que se desfaz. ${ }^{3}$

É a esperança de que esta então já evidente decadência de Portugal fosse revertida que foi depositada em D. Sebastião. Participavam deste estado de ânimo não só Camões, mas também uma série de intelectuais a ele contemporâneos'. Assim, quando o rei desapareceu na batalha de Alcácer Quibir, não foi apenas a existência de Portugal enquanto reino independente que naufragou, fato que se consumaria dois anos depois com a morte do Cardeal D.

$$
\begin{aligned}
& \text { 1.PESSOA, 1983. p.9. } \\
& \text { 2. CMMOSS, 1980. p.77. } \\
& \text { 3. LOURENC,0, 1983. . .104. } \\
& \text { 4. C. PRRSS, 1982. }
\end{aligned}
$$

Henrique, mas todo um conjunto de esperanças de grandeza que fora associado ao rei menino.

É a partir deste contexto que podemos melhor entender os primórdios do mito sebástico. Estes primórdios são descritos de forma bastante clara por Oliveira Martins em seu História de Portugal, livro publicado originalmente em 1879, que aqui escolhemos não só por ser o primeiro que tratou de forma consistente a importância do mito sebástico na história portuguesa, mas também por ser, como veremos, a principal fonte sobre a história portuguesa utilizada por Euclides da Cunha. Nesta obra, ao se referir ao início da União Ibérica, Martins afirma:

(...) o povo, deprimido e miserável, nada confiava nem esperava dos homens: pedia tudo a Deus, e a um milagre.

Como os antigos judeus da Palestina, os Portugueses tinham amassado com as suas lágrimas a quimera do messianismo. Devastada, vencida e por fim vendida, a Nação era um campo santo; os homens como sombras; as agitações messiânicas, espécie de fogos-fátuos que ondeavam no ar, suspensos na atra sombra da noite do infortúnio. Os Macabeus de 1580 não tinham sabido menear a espada; e o povo, perdido o sentimento, da sua realidade, como todo e como força, abandonava-se a esperar a volta do Messias - D. Sebastião, o príncipe encantador, a divina criança, que soubera aspirar para a salvação comum, que viria decerto redimir a Nação!

É deste período a recuperação das trovas de Bandarra, o sapateiro santo, escritas originalmente por volta dos anos 20 do século XVI. Estas trovas anunciavam a chegada do Encoberto, futuro monarca de um Império Mundial Cristão, figura a partir deste momento recorrentemente associada a D. Sebastião.

A partir de então o mito sebástico teve uma profícua história na cultura portuguesa. Num primeiro período, em que hipoteticamente $\mathrm{D}$. Sebastião ainda poderia estar vivo, esperou-se o seu retorno. São desta época os falsos D. Sebastião: o Rei de Penamacor (1584), o Rei da Ericeira (1585), o Pasteleiro do Madrigal (1594) e Marco Tullio Catizone (1598-1602). A crença no retorno do rei menino não será desfeita nem mesmo pela Restauração, em 1640, e permanecerá ao longo da história portuguesa, ganhando fundamentalmente dois

5. MARTINS, s.d. p. 62 
contornos básicos. Por um lado se transmutou na esperança de que D. Sebastião reencarnasse em outro salvador e, ao longo da história de Portugal, muitos foram os chefes políticos que, durante um determinado período, foram assim considerados, entre os quais podemos citar D. João IV, o marquês de Pombal e D. Miguel ${ }^{6}$. Por outro lado, a própria esperança de retomo do rei, que ou teria ficado dormindo em um sono de mistério em algum lugar encantado, ou teria uma vida excepcionalmente longa, não deixou de persistir, ressurgindo em especial nos momentos de grande crise, como no da Invasão Francesa, em que, como afirma José Agostinho de Macedo, vários portugueses esperavam pelo retomo do rei, dirigindo-se para as praias nas manhãs de nevoeiro'.

Se este brevíssimo sumário está muito longe de esgotar mesmo os aspectos fundamentais do Sebastianismo até o início deste século, quando da publicação de Os Sertões, já nos permitirá analisar a forma como Euclides da Cunha se refere a este mito em seu livro.

\section{II - Os dois Brasis ou o Portugal não sebástico}

Extinto em Portugal, ele [o Sebastianismo] persiste todo, hoje, de modo singularmente impressionador, nos sertões do Norte. ${ }^{B}$

No conjunto de Os Sertões as referências ao Sebastianismo são bastante breves. Além de um trecho mais desenvolvido, em que são feitas reflexões sobre a presença deste mito no Brasil e em Portugal, trecho sobre o qual mais tarde falaremos, encontramos três outros momentos em que um possível retorno de D. Sebastião é referido. O primeiro, o único não relacionado com Canudos, descreve o episódio de Pedra Bonita:

Este lugar foi, em 1837 , teatro de cenas que recordam as sinistras

6. A. PIRES, 1982. p. 38. Uma voriante desto posturo foi a de considerar que outro, que nõo $D$. Sebastiōo, fosse o Encoberto profetizodo par Bandorro. Entre estes outros destocco-se D. Joäo IV, sobre o qual forom leitos inímeros documentos proféticos, desda Umo ediçóp ionina
1987, p.89-137.

7. C. PIRES, 1982. p. 195-197.

8. CUNHA, 1979. p.97. solenidades religiosas dos Achantis. Um mameluco ou cafuz, um iluminado, ali congregou toda a população dos sítios convizinhos e, engrimpando-se à pedra, anunciava, convicto, o próximo advento do reino encantado do rei $D$. Sebastião. Quebrada a pedra, a que subira, não a pancadas de marreta, mas pela ação miraculosa do sangue das crianças, esparzida sobre ela em holocausto, o grande rei irromperia envolto de sua guarda fulgurante, castigando, inexorável, a humanidade ingrata, mas cumulando de riquezas os que houvessem contribuído para o desencanto.'

Os outros dois momentos em que D. Sebastião é citado no livro são profecias. Da primeira delas, que Euclides afirma ter copiado de um dos inúmeros cadernos encontrados em Canudos, retiramos os trechos abaixo:

Em verdade vos digo, quando as nações brigam com as nações, o Brasil com o Brasil, a Inglaterra com a Inglaterra, a Prússia com a Príssia, das ondas do mar D. Sebastião sairá com todo o seu exército.

(...)

Neste dia quando sair com o seu exército tira a todos no fio da espada deste papel da República. O fim desta guerra se acabará na Santa Casa de Roma e o sangue há de ir até a junta grossa...10

A segunda profecia é citada junto a outras, também encontradas em Canudos, em que o regime republicano, chamado de a 'lei do cão', é atacado, entre outros motivos, por ter instituído o casamento civil. A parte que se refere a D. Sebastião é composta por duas quadras que abaixo reproduzimos:

D. Sebastião já chegou

E traz muito regimento

Acabando com o civil

$\mathrm{E}$ fazendo o casamento!

(...)

\section{CUNHA, 1979. p.98}

10. CUNHA, 1979. P. 115 
Visita nos vem fazer

Nosso rei D. Sebastião.

Coitado daquele pobre

Que estiver na lei do cão!"

Como podemos notar, estas citações, além de parcas, não nos permitem ter uma visão precisa do que caracterizaria o Sebastianismo como foi assimilado no nordeste brasileiro. Delas podemos apenas depreender que este Sebastianismo está ligado somente a uma das correntes que acima apontamos, aquela que acreditava no regresso de $\mathrm{D}$. Sebastião que teria ficado encantado desde a batalha de Alcácer Quibir. Os incidentes ocorridos em Pedra Bonita mostram claramente este tipo de postura, já que existe um encantamento que precisa ser quebrado para que este rei possa retornar. Além disto parece ser recorrente a idéia de que ele ressurgirá como um chefe militar invencível, capitaneando um exército que com ele ficou encantado: esta imagem aparece não só na narrativa sobre Pedra Bonita, mas também nas duas profecias encontradas em Canudos. Em todos os casos, também, este rei viria para acabar com uma ordem injusta, classificada como humanidade ingrata na narração do episódio de Pedra Bonita, e associada diretamente à República nas duas profecias, sendo que na primeira destas a ordem injusta também é formada pela Igreja Romana, já que será na Santa Casa de Roma que esta guerra terminará.

Certamente, apenas estes parcos elementos não nos permitem ter uma idéia minimamente consistente das características básicas do Sebastianismo como foi assimilado no Brasil. Eles praticamente apenas atestam a existência deste messianismo enquanto a esperança de retorno de um rei salvador que, junto com seu exército, instaurará uma nova ordem.

Euclides da Cunha, em seu livro, de fato não vai além desta constatação, e parece não ter por objetivo explicar as características do Sebastianismo nordestino, mas sim os motivos que permitiram que ele existisse em pleno século XIX. Para isto, de início, considera que a origem deste e de outros messianismos no nordeste brasileiro está ligada ao próprio período em que se realizou a colonização do Brasil:

Considerando as agitações religiosas do sertão e os evangelizadores e messias singulares, que, intermitentemente, o atravessam, ascetas

11. CUNHA, 1979. p. 139. mortificados de flagícios, encalçados sempre pelos sequazes numerosos, que fanatizam, que arrastam, que dominam, que endoudecem espontaneamente recordamos a fase mais crítica da alma portuguesa, a partir do final do século XVI, quando, depois de haver por momentos centralizado a História, o mais interessante dos povos caiu, de súbito, em decomposição rápida, mal disfarçada pela corte oriental de D. Manuel.

O povoamento do Brasil fez-se, intenso, com D. João III, precisamente no momento de fastígio de completo desequilíbrio moral, quando "todos os terrores da Idade Média tinham cristalizado no catolicismo peninsular"."

Se isto justificaria a origem do messianismo presente no nordeste, a sua permanência ao longo dos séculos é explicada pelo insulamento desta região:

Uma grande herança de abusões extravagantes, extinta na orla marítima pelo influxo modificador de outras crenças e de outras raças, no sertão ficou intacta. ${ }^{13}$

Assim, o messianismo nordestino é, para Euclides, fruto de um anacronismo, da permanência de certas características que há muito desapareceram do litoral, como explicita em outro trecho em que está se referindo especificamente à guerra de Canudos:

Insistamos sobre esta verdade: a guerra de Canudos foi um refluxo em nossa história. Tivemos, inopinadamente, ressurreta e em armas em nossa frente, uma sociedade velha, uma sociedade morta, galvanizada por um doudo. Não a conhecemos. Não podíamos conhecê-la. Os aventureiros do século XVII, porém, nela topariam relações antigas (...). (...) essas psicoses epidêmicas despontam em todos os tempos e em todos os lugares como anacronismos palmares, contrastes inevitáveis na evolução desigual dos povos, patentes sobretudo quando um largo

12. CUHHA, 1979. p.96. É no minimo curioso o forma coma Euclides do Cunho monta estes dois porágrofors. Por eles porece que os

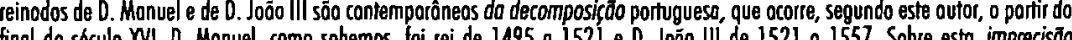
cronologica voltaremos a folar mois ò frente.

13. CUNHA, 1979. p.96. 
movimento civilizador lhes impele vigorosamente às camadas superiores.

(...)

Vivendo quatrocentos anos no litoral vastíssimo, em que pelejam reflexos da vida civilizada, tivemos de improviso, como herança inesperada, a República. Ascendemos, de chofre, arrebatados na caudal dos ideais modernos, deixando na penumbra secular em que jazem, no âmago do país, um terço da nossa gente. (...) tornamos (...) mais fundo o contraste entre o nosso modo de viver e o daqueles rudes patrícios mais estrangeiros nesta terra do que os imigrantes da Europa. Porque não nolos separa um mar, separam-no-lo três séculos...14

Podemos desta forma verificar que a explicação que dá para o messianismo nordestino está intimamente vinculada com a imagem que Euclides da Cunha cria, em seu livro, do Brasil: um país cindido em dois, em que um litoral em contato permanente com os centros mais avançados está justaposto a um interior que mantém práticas culturais que possuem três séculos, um litoral moderno ao lado de um interior anacrônico.

Se muito da crítica moral que faz à campanha de Canudos advém dessa perspectiva, para o assunto que aqui estamos tratando ela possui um outro tipo de interesse. Para provar sua tese, Euclides precisou demonstrar que o messianismo nordestino possuiria elementos há muito erradicados da cultura européia, entre eles o Sebastianismo. É isto o que afirma no trecho que abaixo reproduzimos:

De feito, considerando as desordens sertanejas, hoje, e os messias insanos que as provocam, irresistivelmente nos assaltam, empolgantes, as figuras dos profetas peninsulares de outrora - o rei de Penamacor, o rei da Ericeira, errantes pelas faldas das serras, devotados ao martírio, arrebatando na mesma idealização, na mesma insânia, no mesmo sonho doentio, as multidões crendeiras.

Esta justaposição histórica calca-se sobre três séculos. Mas é exata, completa, sem dobras. Imóvel o tempo sobre a rústica sociedade sertaneja, despeada do movimento geral da evolução humana, ela respira ainda a mesma atmosfera moral dos iluminados que encalçavam, doudos,

14. CUNHA, 1979. p. 137-138. o Miguelinho ou o Bandarra. Nem the falta, para completar o símile, o misticismo político do sebastianismo. Extinto em Portugal, ele persiste todo, hoje, de modo singularmente impressionador, nos sertões do Norte. ${ }^{15}$

O raciocínio de Euclides é assim bastante claro. O Sebastianismo, como os demais misticismos característicos da cultura nordestina, são fruto da permanência nesta sociedade de elementos que já há muito haviam sido erradicados nos espaços que fazem parte do movimento geral da evolução humana. Prova disto é que o Sebastianismo, extinto em sua origem, Portugal, ainda se encontraria vivo no Sertão.

Obviamente é muito fácil, a partir de uma perspectiva contemporânea, mostrar o quanto é falso este raciocínio em relação ao Sebastianismo em Portugal. Basta aqui nos lembrarmos das obras de Teixeira de Pascoaes e Fernando Pessoa, nas quais o Sebastianismo é não só um tema literário central mas também, em vários aspectos, uma saída possível para o país. Esta perspectiva pode ser notada, por exemplo, no poema de Pascoaes sintomaticamente intitulado "Oração sebastianista", publicado originalmente em 1922, poema que nos mostra que D. Sebastião tinha, ainda então, um papel a cumprir para a cultura portuguesa:

Ó meu rei de fantástica memória,

Passo a vida a rezar a tua história,

Tão verdadeira

E sobrenatural...

Eu rezo a tua infância aventureira

Tua morte num trágico areal.

Rezo a tua existência transcendente,

Numa ilha de névoa, ao sol nascente,

Encantada nos longes da Natura...

E rezo a tua vinda anunciada,

Dentre as brumas daquela madrugada

Que virá dissipar a noite escura. ${ }^{16}$

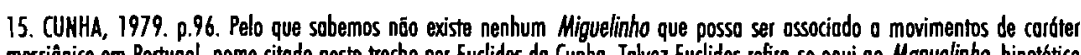

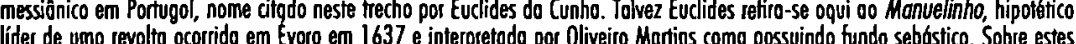

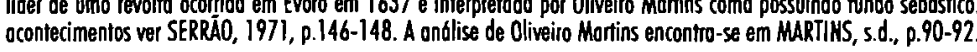
16. PASCOAES, 1922. P. 9. 

que o Sebastianismo não se encontrava, no início deste século, extinto em Portugal, não é por esta via que podemos criticar a perspectiva assumida por Euclides em Os Sertões. Devemos notar que esta nova eclosão do Sebastianismo na cultura portuguesa, de que as obras de Pascoaes e Pessoa fazem parte, de fato é posterior ou, no máximo, contemporânea à publicação deste livro, e certamente poderia ainda não ser conhecida por seu autor, não fazendo assim parte do horizonte cultural a partir do qual esta obra foi escrita. Em relação a esse aspecto devemos assinalar que, se o Sebastianismo sempre esteve mais ou menos presente na cultura lusitana", é de 1902, mesmo ano da primeira edição do livro de Euclides, a obra de cunho claramente profético e sebástico que podemos considerar que inaugura esta revitalização do mito característica do início do século XX: Despedidas de António Nobre, da qual, apenas a título de exemplo, citamos abaixo uma das mais representativas estrofes:

Esperai, esperai, 6 Portugueses!

Que ele há-de vir, um dia! Esperai.

Para os mortos os séculos são meses,

Ou menos que isso, nem um dia, um ai.

Tende paciência! finarão revezes;

E até lá, Portugueses! trabalhai.

Que El-Rei-Menino não tarda a surgir,

Que ele há-de vir, há-de vir, há-de vir!!

Mas, mesmo sem levarmos em consideração obras contemporâneas e/ou posteriores a $O s$ Sertões, e nos restringindo ao horizonte cultural em que este livro foi escrito, ou seja, às obras que Euclides da Cunha poderia ter utilizado como fonte, já poderemos verificar que a concepção por ele expressa, no que se refere à inexistência presente do mito sebástico em Portugal, era uma perspectiva que não correspondia às reflexões então existentes neste país. Como prova disto podemos indicar que a principal fonte utilizada por Euclides para falar do contex to lusitano, o já citado História de Portugal de Oliveira Martins, expressa um ponto de vista bastante distinto.

17. Ver, o este respeito BESSELAAR, 1987; PIRES, 1982 \& OUADROS, 1982

18. NOBRE, 1945. p. 115

\section{III - Portugal e sua morte em Alcácer Quibir}

A derrota de Alcácer! Noite escura

Que sobre nós desceu e em nós ficou,

E é a nossa própria sombra de amargura. ${ }^{19}$

São inúmeras as informações sobre Portugal, presentes em Os Sertões, retiradas de História de Portugal de Oliveira Martins. De fato parece-nos que, ao menos até onde pudemos ir na pesquisa que realizamos para a confecção deste trabalho, é esta a única fonte de que se utilizou Euclides da Cunha para falar da história portuguesa. Vários indícios apontam nesta direção. Oliveira Martins é o único autor português explicitamente citado em Os Sertões, se bem que de forma breve: quando o autor brasileiro utiliza o termo "caquexia nacional", para se referir ao estado dos portugueses após Alcácer Quibir, indica como fonte do mesmo a obra de Oliveira Martins. ${ }^{20}$ Além disto, em outro momento, na parte que já acima citamos em que se refere ao reinado de D. João III, encontramos entre aspas o trecho "todos os terrores da Idade Média tinham cristalizado no catolicismo peninsular", cuja fonte não é indicada, mas que também foi retirado do mesmo livro de Martins. ${ }^{21}$

Se estes são os únicos dois momentos em que temos trechos explicitamente retirados da obra de Martins, de fato todo o discurso de Euclides sobre Portugal está coalhado de referências retiradas do História de Portugal. Apenas para citarmos os exemplos mais flagrantes, são fruto desta obra de Martins a reflexão sobre o papel dos negros na cultura portuguesa e a própria citação que Euclides faz de Garcia de Rezende ${ }^{2 n}$, a imagem do reinado de D. Manuel como um reinado orienta ${ }^{23}$, as referências às visões que o povo de Lisboa tinha de "ataúdes agoureiros, línguas de flamas misteriosas catervas de mouros albornozes brancos" por cima dos passos reais ${ }^{24}$, e as reflexões sobre o rei de Penamacor e sobre o rei da Ericeira, como dissemos dois falsos D. Sebastião ${ }^{25}$.

19. PASCOAES, 1916. p.61

20. CUNHA, 1979. p.97. Este termo foi retirodo de MARTINS, s.d. p.63.

21. CUNHA, 1979. p.97. Este trecho foi retirodo de MARIISS, s.d. p.39.

22. Cf. CUNHA, 1979. p.66. Esto reflexōo e o trecho citado de Gorcio Rezende se encontram em MARTINS, s.d. p. 28.

23. Cf. CUNHA, 1979. p.96. Esto imagem do reinodo de D. Monuel como um reinado oriental pode ser encontroda em MARIINS, s.d. p.16, p.25.

24. CUNHA, 1979. p.97. Estos visöes aporecem em MARTIHS, s.d. p.43-44.

25. đ. CUNHA, 1979. p.97. Estas reflexöes aporecem em MARTINS, s.d. p.63-64. 
Por este inventário, que não é exaustivo, podemos notar que não são apenas referências factuais, mas também várias das interpretaçōes que Oliveira Martins tem sobre eles, que são utilizadas por Euclides em seu livro.

Se esta apropriação do pensamento martiniano poderia indicar um certo desconhecimento de Euclides da Cunha sobre a cultura portuguesa, que o levaria a utilizar recorrentemente como fonte este autor português ${ }^{26}$, a postura de Euclides em relação ao Sebastianismo é totalmente diversa da adotada por Martins, sem que o autor brasileiro apresente nenhuma evidência que explique este distanciamento em relação a uma obra que havia seguido de forma tão subserviente em outras passagens.

Como acima já o dissemos, Oliveira Martins foi o primeiro historiador português a pensar de forma séria sobre a importância do Sebastianismo. A história da nação portuguesa, como é vista em História de Portugal, pode ser dividida em dois grandes períodos: o da dinastia de Borgonha e o da dinastia de Avis. No primeiro, como afirma Paulo Franchetti, Martins considera que "a nação se vai fazendo inconscientemente, ao sabor das paixōes individuais dos reis, sem que saiba exatamente o que está sendo feito"27, enquanto que no segundo, após a Revolução de 1383, em que "começava a vida da nação como um indivíduo completo e equilibrado" ", Portugal já tem consciência de "sua índole característica, expressão da vontade enérgica que lhe vai permitir manter-se como nação independente: a vocação marítima"" "Formado assim para o mar, Portugal duraria enquanto durasse o desígnio que o formou: a exploração e o domínio do oceano." 30 Nesta perspectiva, para Martins, Portugal morre com o desastre de Alcácer, e o país que ressurge após a restauração de 1640 não é mais a mesma nação:

É verdade que a nossa independência restaura-se em 1640. Mas como? De que modo? Atrever-se-á alguém a dizer que é uma ressurreição?

26. Um deslize, existente em $O S$ Sertöes, parece confirmar esta hipótese. Quando estó a discutir o lento povaumento do Brosil temos 0 seguinte thecho:

"Segundo observa Aires de Casal a populoşöo crescio tõo devagor que no época do perda do Sr. D. Sebostiōo (1580)

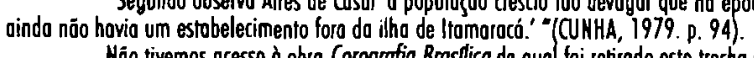

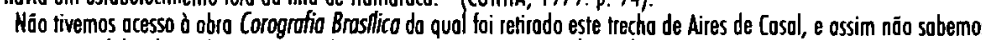
se foi este autor ou Eudides da Cunho quem considerov erroneamente a époco do perda de $D$. Sebostiōo como 1580 e nõa 1578

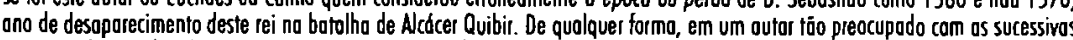
correģöes de sua obra é no mínimo curioso que este deslize tenho passado desapercebido.

27. FRANCHETI, 1995. p.19.

28. FRANCHETI, 1995. p.21.

29. FRANCHETI, 1995. p.21.

30. FRANCHETI, 1995. p.22.
Não será a história da Restauração a nova história de um país que, destruída a obra do império ultramarino, surge no XVI século, como no nosso apareceu a Bélgica, filho das necessidades do equilíbrio europeu? Não vivemos desde 1641 sob o protectorado da Inglaterra? Não chegamos a ser positivamente uma feitoria britânica?"

Se de alguma forma a nação portuguesa ainda existe, não é através deste novo estado criado "sobre o mesmo território e com o mesmo nome e língua"32, mas por estes epitáfios da nacionalidade que são Os Lusíadas e o Sebastianismo:

Acabavam ao mesmo tempo, com a pátria portuguesa, os dois homens - Camões, D. Sebastião - que nas agonias dela tinham encarnado em si, e numa quimera, o plano de ressurreição. Nesse túmulo que encerrava, com os cadáveres do poeta e do rei, o da Nação, havia dois epitáfios: um foi o sonho sebastianista; o outro foi, é, o poema d'Os Lusíadas. A pátria fugira da terra para a região aérea da poesia e dos mitos. ${ }^{33}$

O Sebastianismo se transforma, assim, em um fundo religioso que perpassa a história portuguesa pelo menos desde a derrota de Alcácer até, para Martins, a consumação da vitória liberal, em meados do século passado. Apenas para citarmos dois exemplos que comprovam essa perspectiva de Martins, quando da Restauração, este autor considera que o povo "conservava-se fiel a D. Sebastião; e não faltou quem se recusasse a reconhecer o novo rei [D. João IV], temendo ser desleal ao antigo, ao verdadeiro" ${ }^{34}$. Quando do advento do marquês de Pombal e do terremoto de Lisboa, em 1755, considera que o povo interpretou estes acontecimentos, utilizando-se de uma trova de Bandarra, como sinal do aparecimento próximo de D. Sebastião, sendo Pombal o Anticristo que precedia este momento. ${ }^{35}$ De fato, para Martins, será apenas com a vitória definitiva do liberalismo que o Sebastianismo deixará de existir.

Certamente, se nos lembrarmos aqui da hipótese básica de Euclides da Cunha, de que foi o insulamento do sertão nordestino que permitiu a

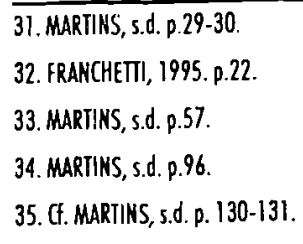


permanência do messianismo e do Sebastianismo nesta região, podemos verificar que a visão de Oliveira Martins, apontando para uma permanência secular do mito sebástico em Portugal, não poderia ser incorporada pelo autor de Os Sertões. Assim, apesar de usar o historiador português como fonte primária não assumida, Euclides simplesmente descarta, sem vir a discutir, a hipótese martiniana, e assume que o Sebastianismo há muito havia desaparecido de Portugal. A sua imagem do Brasil acaba por gerar uma imagem de Portugal: Euclides cria um Portugal não sebástico, pois só um país assim definido caberia nos moldes com os quais tenta explicar não só a revolta de Canudos, mas a própria coexistência de duas realidades totalmente distintas, a do litoral e a do interior, que para ele caracterizam o Brasil.

Por tudo o que aqui dissemos, podemos verificar que Os Sertões, mais do que um documento da presença do Sebastianismo no Brasil - forma através da qual esta obra foi recorrentemente assimilada pela crítica portuguesa ${ }^{36}$ - se constitui, de fato, num manifesto anti-sebástico, já que Euclides da Cunha considerava que o Sebastianismo só poderia ser considerado como algo anacrônico, inconciliável com o tempo cultural que caracterizava o final do século XIX. Certamente não é isto o que a cultura portuguesa, com a nova metamorfose do mito sebástico que ocorre nos primeiros decênios deste século, demonstra. D. Sebastião ainda tinha, como já o dissemos, uma missão por cumprir para esta cultura.

\section{ABSTRACT: \\ This article intends to analyze how Sebastianism appears in Os Sertões and the relations between this book and its principal source of Portuguese history, Oliveira Martins' História de Portugal. KEY WORDS:}

Sebastianism, Euclides da Cunha, Oliveira Martins

\author{
REFEREANCIAS BIBLIOGRÁFICAS: \\ BESSELAAR, José von den. O sebastionismo - Histório Sumário. Lisboa: Instituto de Cultura e Línguo Portugueso, 1987. \\ CAMÖES, Luís de. Os lusiados. Rio de Joneiro: Biblioteco do Exército, 1980.

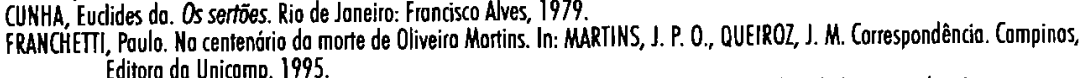 \\ Editoro do Unicomp, 1995.

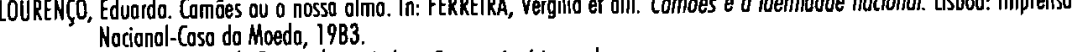 \\ MARTINS, Oliveira. Historia de Portugol. v.2. Lisboo: Europo-Américo, s.d. \\ NOBRE, António. Despedisas. 4. ed. Parto: Imprenso Moderno, 1945, \\ PASCOAES, Teixeiro de. Aos lusiodos. A tguvio, $2^{\circ}$ série, Porto, v.10., n.56, p. 57-61, ogo. 1916. \\ PASCOAES, Teixeiro de. Orosçá Sebostionisto. A A guvio, $3^{\circ}$ série, \\ PIRES ,

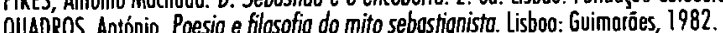 \\ SERRËO, Joel de. Diciontrio de historio de Portugal. v.2. Lisboo: Iniciotivas Editariois, 1971
}

36. Esta perspectivo oparece, por exemplo, em PIRES, 1982, p.425-426 e QUADROS, 1982. p.226-237. 